\title{
ONLINE PEER ASSESSMENT IN A FIRST CYCLE UNIVERSITY DEGREE - WHICH CHALLENGES?
}

\author{
Maria de Jesus C. Relvas, Maria do Carmo Teixeira Pinto, Isolina Oliveira, Alda Pereira, \\ Laboratório de Educação a Distância e eLearning, Universidade Aberta, Portugal
}

\section{Abstract}

Authenticity and transparency constitute two essential dimensions in the digital assessment of competences. Authenticity emphasises the importance of the complexity inherent to online assessment tasks related to real life contexts and are recognised as relevant by students, teachers and potential employers. Transparency has to do with the students' involvement in the assessment tasks, through the democratisation and knowledge of the used strategies.

Self-, co- and peer assessment are powerful instruments in the transparency operationalisation.

The current study presents the peer assessment (PA) implementation process in a first cycle university degree curricular unit, in online context. The study was planned according to the following purposes: (a) to identify peer assessment potentialities and constraints in first cycle university degrees; (b) to analyse the questions that are brought forward among students by the application of a scoring rubric; (c) to reflect on the obtained results, aiming at the improvement of the implementation process and its applicability to other curricular units. In this essay, the authors present and discuss the obtained results, and propose recommendations to improve the quality of the peer assessment process.

Keywords: authenticity; peer assessment; scoring rubric; transparency.

\section{Introduction}

In general, the student assessment in Higher Education has been carried out by teachers, and the students' role in the process has been small. However, as Dochy, Segers, and Sluijsmans (1999) state, peer assessment, defined "as a way whereby students assess the quality of their colleagues' performance and give feedback to one another”, assumes a growing importance within the process of continuous assessment. The disadvantages that are sometimes pointed out regarding peer assessment, according to 
Panadero, Romero, \& Stribjos (2013), are not intrinsic to Higher Education, due to the maturity and capability of young adults. Moreover, another argument is related to the fact that, in the world of work, each individual assesses both his/her own work and his/her peers'. Thus, it is of utmost importance that students can develop assessment competences (Boud, 2000; Boud \& Falchikov, 2006).

Within the scope of the project "Avaliação Digital de Competências (@DiC)” / "Digital Assessment of Competences (@DiC)”, the authors have implemented diverse forms of assessment in Second and Third Cycle curricular units of different university courses, in online contexts, at Universidade Aberta de Portugal (UAb). This work, supported by research (Pereira et al., 2015), has led to relevant conclusions, namely and above all the influence that the students' different backgrounds plays in their views on PA and their involvement in this form of assessment, as well as the importance in establishing trust, both among themselves and between them and the teacher. The preliminary study here presented is within this line of research and was developed in a curricular unit of the First Cycle Degree in Humanities at UAb, according to the following purposes:

16. to identify potentialities and constraints in the use of peer assessment in first cycle university degrees;

17. to analyse the questions that are brought forward among students by the application of a scoring rubric;

18. to reflect on the obtained results, aiming at the improvement of the implementation process and its applicability to other curricular units.

This paper begins with the presentation of the essential concepts that sustain the empirical part of the study; then, it describes and justifies the methodological options; afterwards, it explains and analyses the obtained results. Its final part contains some reflections and consequent recommendations that involve theoretical concepts, as well as conclusions of previous studies.

\section{Conceptual Framework}

In the digital assessment of competences two essential dimensions are authenticity and transparency, due to the following reasons: authenticity refers to the similitude degree among the competences to be assessed and the competences that are required in everyday and in professional life, where the type of assessment tasks is relevant; transparency is related with visibility and understandability, regarding everyone involved, the students, in particular. Therefore, it is important that students have the notion of justice while assessing, that they know and take part both in the definition of criteria and their scores. Peer assessment, such as self- and co-assessment, is part of the necessary strategy that aims at the transparency of digital assessment of competences. The online assessment facilitates 
the students' communication with their peers, as well as the reflection and consequent improvement of their work, based on the peers' feedback (Pereira, Tinoca, \& Oliveira, 2016).

PA is accomplished in authentic tasks "in which the desired evidence of learning is to have students demonstrate an ability to generate ideas or produce a product, such as answer open-ended questions, write an essay, submit a report, design an artifact, engineer a process, or solve an ill-defined complex problem" (Suen, 2014; p.316). Moreover, PA is understood as a process in which a student assesses another student's work, according to adequate and normalised criteria, devised to assess the quality of such work (Topping, 2013). This process "involves students in assessment, generates feedback that might be useful to the evaluated peer, and also gives the peer assessor insights as to how their own work might be improved" (Panadero \& Brown, 2017; p. 134).

In a study on the use of PA in several Higher Education scientific areas, Lladó et al. (2014) conclude that students consider it positive, recognising not only its potential in the motivation and learning, but also its support in the reflection on their learning processes. There are, however, other aspects highlighted by the students, such as anxiety and discomfort, as a consequence of their peers' assessment. In the same line of thought, Panadero, Romero, and Stribjos (2016) emphasise the fact that sometimes the students do not accept the responsibility of assessing their peers, considering it unjust and revealing insecurity when their works are assessed by peers. These issues are particularly relevant when PA constitutes a part of the student's final assessment (Topping, 1998). It is therefore crucial that the scores assigned by the peers are reliable and not biased due to personal relationships. Several studies (Topping, 2003; Falchikov \& Goldfinch, 2000; Suen, 2014) show that PA is reliable and valid, since it complies with adequate conditions.

An essential aspect that must be taken into account in the PA implementation is related with the establishment of scoring rubrics. Scoring rubrics use descriptive ranges that show the students what is relevant in the tasks and specify both the strong and the weak aspects of the work to be assessed. Scoring rubrics should be simple and clear, efficient while used, and should limit the tasks that each student has to accomplish (Suen, 2014). In the elaboration of a rubric one has to consider the validity (one has to check whether it measures what is supposed to be measured), the reliability (one has to check whether the results are consistent in time and through different peers) and the usability (Yuan \& Recker, 2015).

Synthesising the above mentioned aspects, PA contributes to the development of competences, such as the ability to: criticise and to accept criticism; argue on one's own point of view; reject other suggestions whenever justified. Furthermore, PA promotes 
learning self-regulation and personal responsibility, mainly when a good feedback is produced (Nicol, 2010); simultaneously, it increases self-confidence and confidence among peers.

\section{Methodology}

This work is focused on the use of PA in the context of a First Cycle Degree online curricular unit at Universidade Aberta (UAb). According to the UAb Virtual Pedagogical Model, the first cycle degree students may choose the assessment modality: continuous assessment or final exam. Continuous assessment is based on works ( 2 our 3 ) that the students have to produce within the semester - e-folios - and on a final work at the end of the semester (should they obtain a minimum score in the e-folios, stipulated by the institution). At the beginning of each curricular unit, the students are informed of the competences to be developed, the programme, the methodology, the bibliographic materials and the assessment characteristics. All these elements are contained in an online document in the virtual space of the curricular unit, entitled Curricular Unit Plan.

The researchers decided to develop a pilot study in a 1st year curricular unit - Classical Studies II - of the Degree in Humanities, with the following purposes, in order to define strategies for the implementation of the process in other first cycle degree curricular units: the analysis of the continuous assessment students' receptivity regarding PA; the analysis of the questions that are brought forward among students by the application of rubrics.

Bearing in mind that it is a 1st year curricular unit, the researchers opted for the use of PA in general competences, transversal to the study area, having excluded the scientific contents field of the curricular unit; they also opted for the implementation of PA according to a formative perspective, on a voluntary basis, aiming at avoiding possible tensions inherent to a summative assessment. There were 2 e-folios, consisting in the elaboration of short essays on the subjects under study. According to the curricular unit assessment, 5 criteria were defined to support PA: (a) the accomplishment of the proposed task, bearing in mind the stipulated purposes; (b) the construction of argumentative speech; (c) the selection of data/bibliographic material, relevant to the task; (d) the application of citation rules, according to the recommended manual of style; (e) the organisation of the bibliographic materials, according to the recommended manual of style.

The operationalisation of these criteria gave origin to a rubric, and each criteria was thoroughly described, according to three levels: insufficient; good; very good. Specific information on PA was introduced in the Curricular Unit Plan, so as the students could be aware of the proposed assessment modality since the very beginning of the semester, namely on the transversal nature of the competences to be assessed and on the formative 
aspect intrinsic to PA. A specific forum was also created at the beginning of the semester, so as the students could ask questions on PA and discuss its specificities with the teacher. In this forum, the teacher had also the opportunity to motivate the students regarding PA, emphasising its advantages, particularly in self-assessment and in the acquisition of competences. The Moodle Workshop was the technical tool chosen by the researchers to the PA process and was set up to anonymous/blind grading.

An online questionnaire to collect data was produced by the researchers and made available to the students at the end of the semester. It was constituted by 9 questions (7 close-ended, 3 open-ended). The questionnaire was anonymous and approved by the Ethics Commission of Laboratório de Educação a Distância e eLearning. The close-ended questions were on general demographic data, including: age; gender; previous experience in PA and in UAb; participation in the PA activities. Amidst the open-ended questions, one was related to the students' perception on the PA use and to future perspectives of PA use. This question was built in terms of statements, asking for agreement according to a fivepoint Likert scale: strongly agree; agree; neither agree nor disagree; disagree; strongly disagree. The statements for this question are presented in the section on the data analysis.

Two of the open-ended questions were intended for the students who participated in PA, asking them about the positive and negative aspects of the process. The third open-ended question was intended for the students who did not participate in PA, asking them to indicate the reasons for their option.

\section{Data analysis and interpretation}

The curricular unit had 29 enrolled students. 23 of them had chosen continuous assessment. 15 students, predominantly women (10), responded to the questionnaire. Most of the students were age 40 or younger (4 were age 30 or younger); the other 2 were older than age 50. 11 students were attending the university for the first time, and only 1 student had already participated in PA activities. Among the 15 respondents, 7 indicated that they had participated in the PA process. 


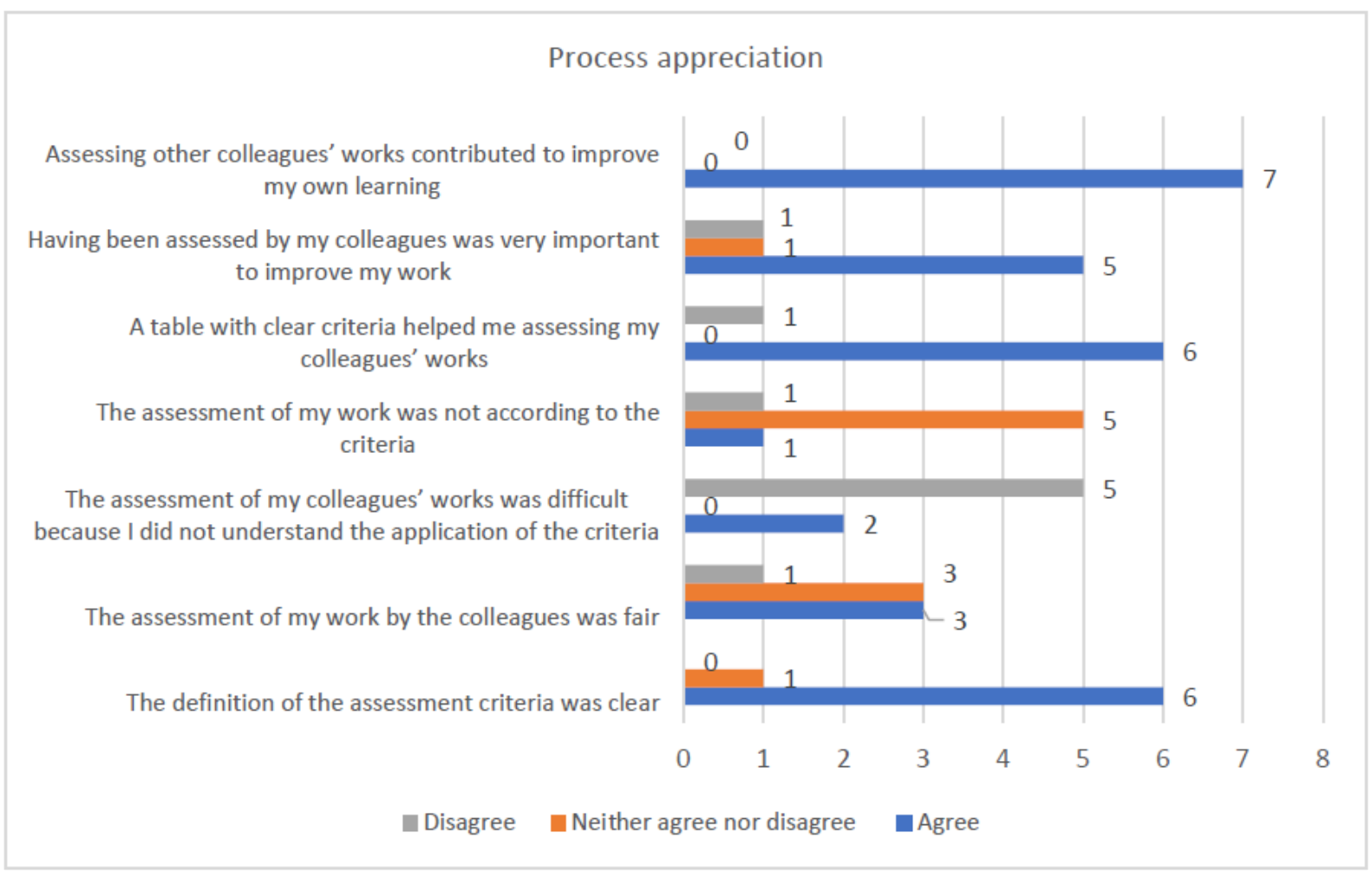

Figure 1. Students' perception on the PA participation

Due to the small number of respondents who indicated their participation in PA, we decided to group the Likert scale levels as follows: agree, disagree, neither agree nor disagree

As one can see, the importance of the PA process is unanimously pointed out by the students. The large majority of the respondents considers that a scoring rubric, with clear criteria, is relevant to the accomplishment of the PA process. However, the students' perception changes when they approach their colleagues' assessment. As a matter of fact, it seems that they do not entirely trust their peers, due to the lack of clear assumptions regarding the fairness of the assessment. On the other side, although the students understand that the criteria were clear and that they had no difficulty in the PA process, there is a contradiction here, once they do not assume that the assessment was not accomplished according to the criteria. From our point of view, this fact may reveal some kind of insecurity regarding their colleagues' assessment, reinforcing the lack of confidence in the peers.

As for the students' opinion regarding a future use of the PA process, Figure 2 synthesises the obtained answers. 


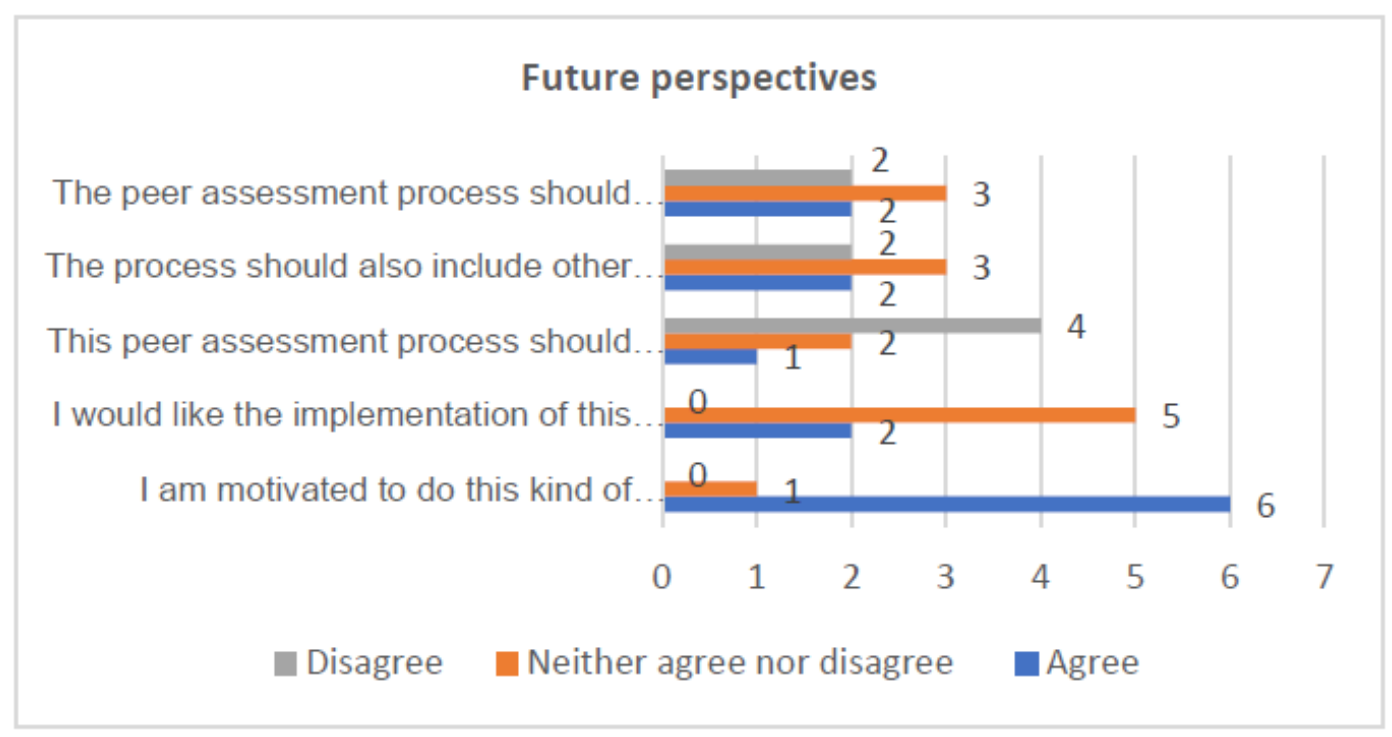

Figure 2. Students' opinion on the future use of the PA process

Although practically all the students considered that they would like to do PA more frequently, the responses show a great diversity regarding a possible wider range of contents, other competences or other curricular units. This seems, once again, to indicate insecurity throughout the process and some lack of confidence and confirms the analysis of the way the students dealt with the experience. Even though the formative use of PA is not called into question, this insecurity may justify a clear disagreement regarding the possibility of summative PA.

Some responses highlight a deep unfamiliarity with PA, as clearly exemplified by some of the statements. A student referred the need of research on the matter, despite the teacher's elucidations on the process - "Once it was the first time I dealt with PA, I felt the need of a thorough research on the process in the internet. Along with the information in the curricular unit, my individual research helped me a lot (student A1). Taking the negative aspects of the process into account, several students refer the fear of not being fair, while assessing - "The lack of time and the fear of being unfair" (student A3); they also refer the distrust of their colleagues' assessment - "I did not agree with the assessment of my first work" (student A2).

Nevertheless, the same students emphasise the positivity of the experience concerning the impact on their own learning, as the following statement shows: "This assessment process led me to improve my skills, namely in the fields of rigour and attentiveness, while elaborating my works" (student A1). Three other students also refer the possibility of knowing different perspectives, while another student adds the benefits of comparing one's work with the colleagues' - "I could see how my colleague wrote the work and I could compare it with mine, thus becoming aware of my interpretation and which was my level (student A4). 
The reasons given by some students who did not wish to participate in the PA process have to be underlined. Among this three of them refer the lack of time for an extra activity and the fear of being unfair while assessing; two refer the fear of criticising their colleagues and of being unfair while assessing; one mentions the optionality of PA, another one the formative (and not summative) grading, and a student recognises the failure to understand the process.

The need of a thorough clarification was also mentioned at the beginning of the semester, in the PA forum. The teacher answered every question. While the process was being accomplished, some students asked for technical support regarding the Moodle Workshop, which was considered not entirely user-friendly by some of them.

\section{Conclusions and final reflections}

The purpose of this work was a preliminary study regarding the PA application in first cycle university degrees, in online context, observing both the students' adherence and their constraints and difficulties. Taking the data above analysed into account, the students who participated in the PA process considered it important and are in favour of its future use. As we have mentioned, the availability of a scoring rubric helped the PA implementation.

However, the obtained data require some reflection. Despite all the initial information and the teacher's elucidations in the PA forum, a few students had eventually some doubts and were unsure of the process, regarding not only the application of the scoring rubric, but also the fairness inherent to their colleagues' assessment. This insecurity and lack of confidence is also patent in the assertive refusal of the PA process implementation in other competences or curricular units. The students who did not participate underlined both their fear of being unfair and the time issue. The latter may be directly connected with the UAb students' general profile: adults, who have to organise their time very carefully, and thoroughly articulate the learning activities with their personal and familiar ones.

We may assume that several students, when facing a situation which implies that assessment is not exclusively accomplished by the teacher, undervalue the possibility of participation or even consider that it is the teacher who should carry it entirely out.

This and the fact that only 8 out of the 23 students participated in the PA process highlights the importance of dedicating a longer period of discussion with the students, before the process is implemented, in order to approach not only the procedures, but also the scoring rubric. The worthiness of PA to the learning self-regulation has to be emphasised, so as the students' motivation to adhere to it may increase. In this context, one should consider the possibility of synchronous sessions with the students, to facilitate the debate on the matter, 
through questions, comments and clarifications. Once that at the UAb the online context is essentially asynchronous, such an option may lead to a greater involvement on the part of the students, and may promote their trust, both among them and between them and the teacher.

Beyond these aspects, it is important that the PA process is implemented simultaneously with the students' self-assessment, because, with a common scoring rubric, the students will be able to compare their own assessment with their colleagues'. The implementation of the scoring rubric will be clearer when articulated with a mandatory qualitative feedback, thus promoting a deeper reflection on the accomplished assessment.

\section{References}

Boud, D. (2000). Sustainable assessment: Rethinking assessment for the learning society. Studies in Continuing Education, 22(2), 151-167.

Boud, D. \& Falchikov, N. (2006). Aligning assessment with long-term learning. Assessment \& Evaluation in Higher Education, 31(4), 399-413.

Dochy, F., Segers, M., \& Sluijsmans, D. (1999). The use of self-, peer- and co-assessment in higher education. A review. Studies in Higher Education, 24(3), 331-350.

Falchikov, N., \& Goldfinch, J. (2000). Student peer assessment in higher education: A meta-analysis comparing peer and teacher marks. Review of Educational Research, 70(3), 287-322.

Lladó, A. P., Soley, L. F., Fraguell Sansbelló, R. M., Arbat Pujolras, G., Pujol Planella, J., Roura-Pascual, N., Suñol Martínez, J. J., \& Montoro Moreno, L. (2014). Student perceptions of peer-assessment: an interdisciplinary study. Assessment \& Evaluation in Higher Education, 39(5), 592-610.

Nicol, D. (2010). From monologue to dialogue: improving written feedback processes in mass higher education. Assessment \& Evaluation in Higher Education, 35(5), 501-517.

Panadero, E., Romero, M., \& Strijbos, J. W. (2013). The impact of a rubric and friendship on construct validity of peer assessment, perceived fairness and comfort, and performance. Studies in Educational Evaluation, 39(4), 195-203. doi:10.1016/j.stueduc.2013.10.005

Panadero, E., \& Brown, G. T. L. (2017). Teachers' reasons for using peer assessment: positive experience predicts use. European Journal Psychology Educational, 32, 133156. 
Pereira, A., Oliveira, I., Tinoca, L., Pinto, M. C., \& Amante, L. (2015). Desafios da avaliação digital no Ensino Superior. Lisboa: Universidade Aberta. Disponível em Retrieved from https://repositorioaberto.uab.pt/handle/10400.2/5774

Pereira, A., Tinoca, L. \& Oliveira, I. (2016). Peer assessment in an online context: what do students say? In E. Cano, \& G. Ion (Eds.), Innovative Practices for Higher Education Assessment and Measurement (pp. 248-270). ICI Global.

Suen, H. K. (2014). Peer Assessment for Massive Open Online Courses (MOOCs). IRRODL, 15(3), 312-327. Retrieved from http://www.irrodl.org/index.php/irrodl/article/view/1680

Topping, K. J. (1998). Peer assessment between students in colleges and universities. Review of Educational Research, 68(3), 249-276.

Topping, K. J. (2003). Self and peer assessment in school and university: Reliability, validity, and utility. In M. Segers, F. Dochy, \& E. Cascallar (Eds.), Optimising new modes of assessment: In search of qualities and standards (pp. 55-87). Dordrecht, Netherlands: Kluwer. Springer Netherlands.

Topping, K. J. (2013). Peers as a source of formative and summative assessment. In J. H. McMillan (Ed.), The SAGE handbook of research on classroom assessment (395-412). Thousand Oaks, CA: Sage.

Yuan, M, \& Recker, M. (2015). Not all rubrics are equal: a review of rubrics for evaluating the quality of open educational resources. IRROLD, 16(5). https://doi.org/10.19173/irrodl.v16i5.2389

\section{Acknowledgement}

This research is integrated in the Portuguese R \& D unit 4372/FCT Laboratório de Educação a Distância e eLearning, Universidade Aberta, financed by Foundation for Science and Technology. 